\title{
Study of P (VDF-HFP)/CNTs Composite Microporous Polymer Electrolyte for Li-Ion Batteries
}

\author{
Kan Kan, Ying Liu, Yuan Tian, Qiushi You, and Baoyu Cui
}

\begin{abstract}
This paper reports the synthesis and performance of microporous polymer electrolyte (MPE) based on P(VDF-HFP)/CNTs Li-ion batteries. The MPE based on P(VDF-HFP)/CNTs has an interconnected uniform porous morphology with an average diameter. The MPE based on P(VDF-HFP)/CNTs with the CNTs content of $3 \%$ shows ionic conductivity of $4.36 \times 10^{-3} \mathrm{~S} / \mathrm{cm}$. The MPE is stable at the higher potential more than $5.5 \mathrm{~V}$ (versus $\mathrm{Li}^{+} / \mathrm{Li}$ ). The discharge capacity of $\mathrm{LiFePO}_{4}$ in the cell $\mathrm{Li} / \mathrm{GPE} / \mathrm{LiFePO}_{4}$ is $140 \mathrm{mAh} / \mathrm{g}$ at the charge-discharge rate of $0.1 \mathrm{C}$. The prepared MPEs are promising materials for $\mathrm{Li}$-ion batteries.
\end{abstract}

Index Terms-P (VDF-HFP), CNTs, polymer electrolyte, li-ion battery.

\section{INTRODUCTION}

Microporous polymer electrolyte (MPE) with its microporous structure to absorb and fix liquid organic solvents as electrolyte has been attracting continuous attention [1]. MPE has higher ionic conductivity than solid polymer electrolyte and higher stability than liquid electrolyte, providing a solution to safety problems [2]. Many polymers have been reported to be used as MPEs, such as poly (vinylidene fluoride) (PVDF) [3] and polyvinyl chloride (PVC) [4]. The copolymer such as poly (vinylidene fluoride-hexafluoropylene) (P (VDF-HFP)) [5] perform well as the electrolyte materials. The P (VDF-HFP) as a host have increasingly being investigated. P (VDF-HFP) itself has a high dielectric constant, and comprises both an amorphous and a crystalline phase; the amorphous phase of the polymer assists higher ionic conduction whereas the crystalline phase acts as a mechanical support for the polymer electrolyte. The ionic conductivity of the copolymer P (VDF-HFP) can be enhanced by doping with inorganic oxides, such as $\mathrm{TiO}_{2}[6]$, [7], $\mathrm{SiO}_{2}$ [8], $\mathrm{SnO}_{2}$ [9] and $\mathrm{CeO}_{2}$ [10]. CNTs have unique structural features, such as nano-scale, large aspect ratio, and can overlap with each other form a network. The host structure plays a vital role in the enhancement of the ionic conductivity of the composite polymer electrolytes. Therefore, an attempt was made to study the effect of the CNTs on ionic conductivity and the compatibility with the composite polymer electrolytes. The performance of the composite membrane and its MPE for Li-ion battery use were studied.

Manuscript received Januray 3, 2013; revised March 1, 2013.

K. Kan, Y. Tian, Q. S. You and B. Y. Cui are with the Daqing Branch of Heilongjiang Academy of Sciences, DaQing, China (e-mail: kankan5758@ yahoo.cn, tylovezcs@163.com, perfect_you@126.com, cuibaoyu1962@ yahoo.com.cn).

Y. Liu is with the Heilongiiang Academy of Sciences, Harbin, China (e-mail:happyavi@163.com).

\section{EXPERIMENTAL}

\section{A. Materials Preparation}

P(VDF-HFP) (Kynar2801, Japan) was dissolved in acetone and stirred for $1 \mathrm{~h}$ at $60^{\circ} \mathrm{C}$. A certain concentration of CNTs(1wt.\%, 2wt.\%, 3wt.\%, 4wt.\% and 5wt.\%) was dispersed in the mixture by ultrasonic. and stirred for $2 \mathrm{~h}$. The mixture was magnetically stirred for $6 \mathrm{~h}$. The resultant viscous homogeneous solutions were cast as a film on a glass substrate. The prepared films were kept at $60^{\circ} \mathrm{C}$ under $10^{-3}$ Torr pressure for $18 \mathrm{~h}$ in vacuum in order to evaporate the solvent. The dried samples were subjected for the following characterizations. The samples were named as C-1, C-2, C-3, C-4, C-5. P(VDF-HFP) without CNTs was also prepared for comparison, and named as $\mathrm{C}-0$.

\section{B. Characterization}

The morphology was characterized by scanning electron microscopy (SEM, HITACHI S-4800). The crystallinity was characterized by X-ray diffraction (XRD, D/max-III B-40 KV, Japan). Thermogravimetric analysis (TGA, Netzsch TG209F3) was carried out to survey the thermal stability. The electrolyte uptake of MPEs was calculated by: $\mathrm{Q}=$ $\left(\mathrm{W}-\mathrm{W}_{0}\right) / \mathrm{W}_{0} \times 100 \%$. The $\mathrm{W}_{0}$ and $\mathrm{W}$ were the mass of the dry and wet membranes. The electrochemical measurements were carried out on an electrochemical instrument (CHI660, Shanghai). The ionic conductivity was measured by the AC impedance method using stainless steel (SS) electrode. The compatibility was determined by the linear sweep voltammetry with the cell $\mathrm{Li} / \mathrm{MPE} / \mathrm{Li}$. The cell of $\mathrm{Li} / \mathrm{MPE} / \mathrm{LiFePO}_{4}$ was set up and charge-discharge test was carried out using Land Battery Test System (Wuhan Land Electronic Co. Ltd.).

\section{RESULTS AND DISCUSSION}

\section{A. Material Characterizations}

Fig. 1 presents the SEM images of C-0 and C-3 membranes. It can be seen from Fig. $1(a, b)$ that there are non-uniform pores on the surface of the C-0 membranes. After doping CNTs in the amount of $3 \mathrm{wt}$. \%, the pore morphology exhibits great difference. There are some interconnect pores under the membrane, as shown in Fig. 1(c). The formation of interconnect pores due to the intercalation behavior of long-chain copolymer and CNTs. And the uniform porous structures on the composite films are shown in Fig. 1(d). The pores are separated and spherical with the diameter $2-3 \mu \mathrm{m}$. It is suggested that the pore structure of the 
P (VDF-HFP) membrane can be improved by the doping suitable amount of the CNTs.

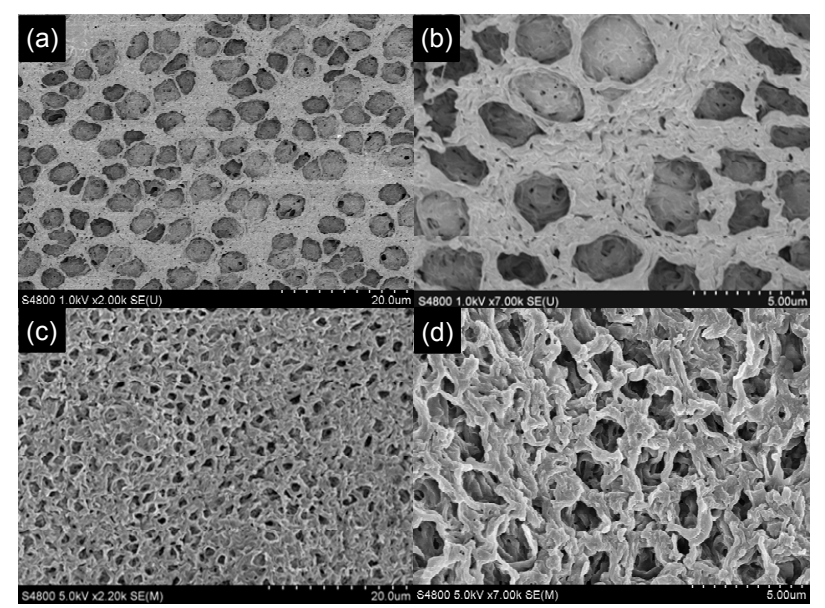

Fig. 1. SEM surface images of composites porous membranes: $(\mathrm{a}, \mathrm{b}) \mathrm{C} 0$ and (c, d) C3.

The crystal structures of P (VDF-HFP)/CNTs composites membranes were determined by XRD analysis. As shown in Fig. 2, the diffraction patterns of all prepared membranes are similar. The diffraction peaks at $18.2^{\circ}, 19.8^{\circ}$, and $26.2^{\circ}$ correspond to the reflection of (020), (021), and (201) planes, typical for the orthorhombic cell of PVDF. The pure $\mathrm{P}$ (VDF-HFP) is highly crystalline; however, when composite with CNTs, the degree of crystallinity is greatly reduced. The degree of crystallinity is decreased and broader with increasing content of CNTs. The diffraction patterns could be decomposed into amorphous. The lower crystallinity of the polymer electrolyte is expected to contribute high ionic conductivity to the MPE based on P (VDF-HFP)/CNTs composites.

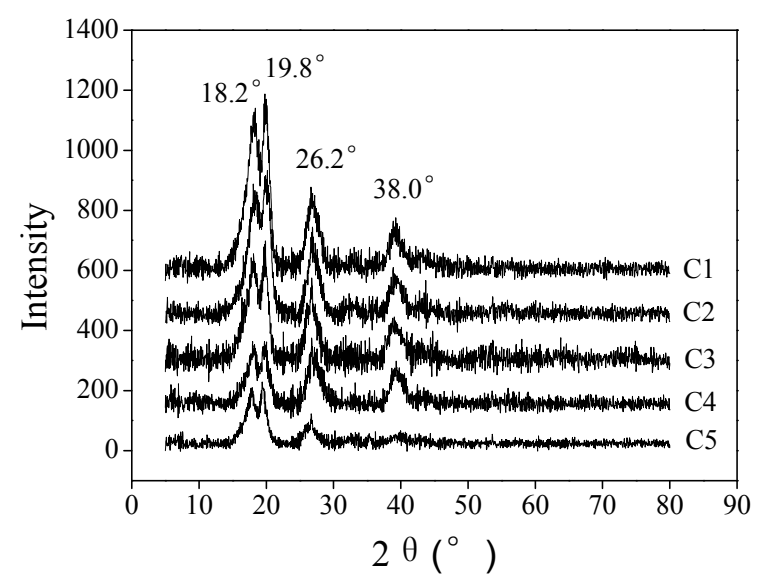

Fig. 2. XRD curves of P(VDF-HFP)/CNTs composites porous membranes.

\section{B. Electrochemical Characterizations}

The electrolyte uptakes and ionic conductivities of the MPEs based on P (VDF-HFP)/CNTs are shown in Fig. 3. It can be seen from Fig. 3(a) that the electrolyte uptake of the $\mathrm{C}-0$ is the lowest. The electrolyte uptake of $\mathrm{C}-1$ is $187.2 \%$ and increases to $219.0 \%$ when the concentration of CNTs is $3 \%$. As the content of CNTs increases further, the electrolyte uptake decrease slowly. The electrolyte uptake of the MPEs is related to its porous structure and affinity to electrolyte. The CNTs as a layered frame helps to form larger three-dimensional porous structures, which result in the improvement of the electrolyte uptake ability. The uniform porous structures of composite membranes provide stronger affinity to electrolyte. However, when the addition amount of CNTs was over 3\%, the CNTs indicate agglomerate state. This might reduce the electrolyte uptake. It can be noted from Fig. 3(b) that the ionic conductivity of the C-3 is $4.36 \times 10^{-3} \mathrm{~S} / \mathrm{cm}$, which is larger than other MPEs. The variation trend is nearly the same as their electrolyte uptake. This may be ascribed to porous connectivity of MPEs. The agglomerate action of CNTs may break the interconnection of the pores in the MPE, which may lower ionic conductivity.

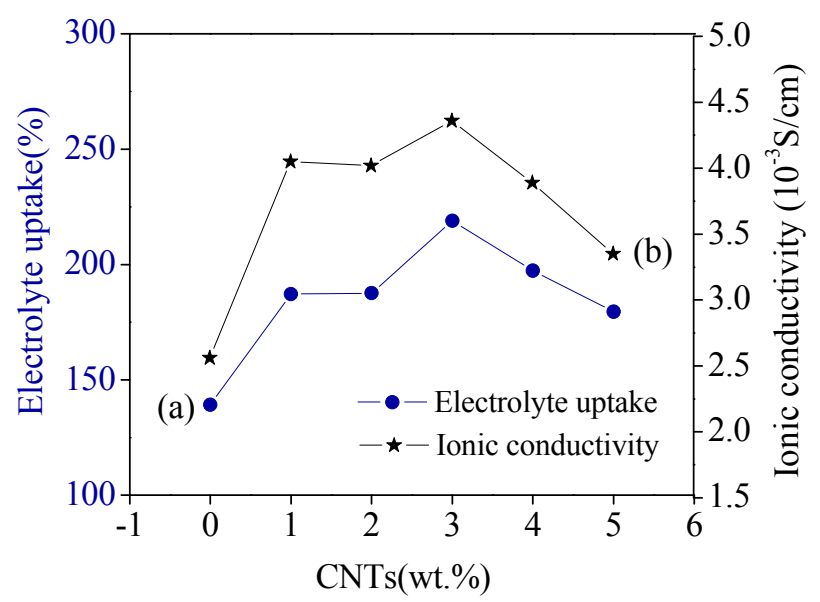

Fig. 3. Variation of electrolyte uptake (a) and ionic conductivity (b) of MPEs based on P(VDF-HFP)/CNTs composites with different contents of CNTs.

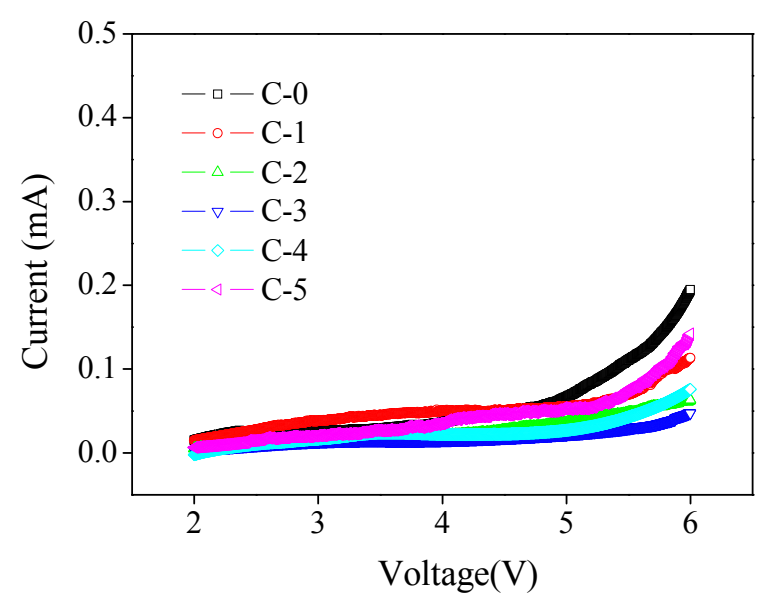

Fig. 4. Linear voltammograms of composite polymer electrolyte membranes.

Fig. 4 presents the linear voltammograms obtained for the cell $\mathrm{Li} / \mathrm{MPE} / \mathrm{Li}$ with $\mathrm{C}-0, \mathrm{C}-1, \mathrm{C}-2, \mathrm{C}-3, \mathrm{C}-4$ and C-5. It can be seen from Fig.5 that the MPE with P(VDF-HFP) discomposes at about 5.0V. Obviously, the MPEs based on the P(VDF-HFP)/CNTs composite exhibit an anodic stability $\geqslant 5.4 \mathrm{~V}$, which are greater than that of $\mathrm{P}(\mathrm{VDF}-\mathrm{HFP})$. This can be ascribed to the excellent affinity of the membrane to the electrolyte that is partially dissolved in the pore of composite membrane. The MPE based on $\mathrm{P}$ (VDF-HFP)/CNTs has better electrochemical stability than the MPE based on P(VDF-HFP), suggesting that the synergistic effect of CNTs and P(VDF-HFP) in the composites membrane.

The cell $\mathrm{Li} / \mathrm{MPE} / \mathrm{Li}$ was set up and $\mathrm{AC}$ impedance spectroscopy was used to monitor the change in impedance 
with time. The initial impedance behavior of MPE based on C-0 and C-3 at ambient temperature are shown in Fig. 5. Both of the samples display similar curvature but the diameter of the semicircle different. The initial interfacial resistance is $278 \Omega$ and $392 \Omega$ for the MPE based on C-0 and C-3, respectively. The evolution of the interfacial resistance with storage time is shown in the inset of Fig. 6. It can be seen that the MPE based on C-3 has the less change in interfacial resistance compared with $\mathrm{C}-0$. This indicates that the MPE based on $\mathrm{C}-3$ has better compatibility with Li electrode than $\mathrm{C}-0$. The resistance of the MPEs based on C-0 and C-3 increases within two weeks but keeps almost unchanged after two weeks. This suggests that it takes two weeks for the formation and stabilization of MPE on Li. This confirms that the C-3 can function as an efficient ion transport media between the electrodes.

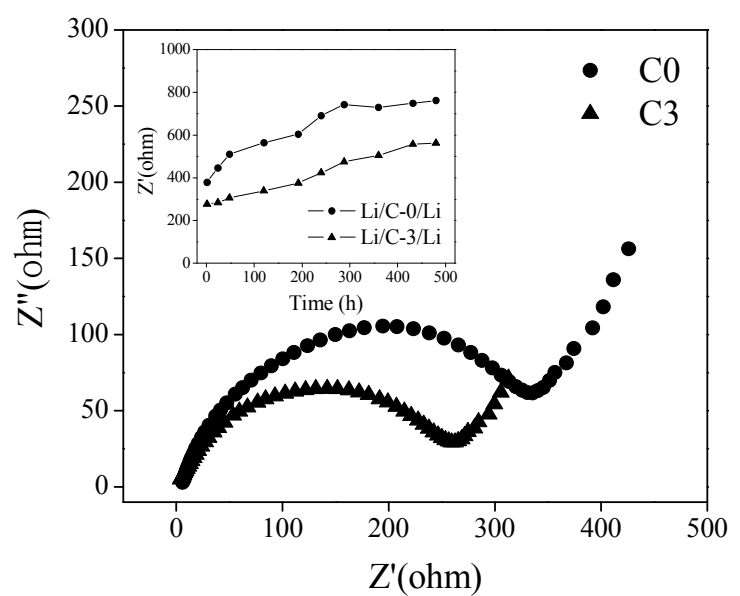

Fig. 5. Impedance spectra of cell $\mathrm{Li} / \mathrm{MPE} / \mathrm{Li}$ at open circuit potential with $\mathrm{C}-0$ and C-3; Inset: the variation of interfacial resistance of cell $\mathrm{Li} / \mathrm{MPE} / \mathrm{Li}$ with storage time.

\section{Battery Performance}

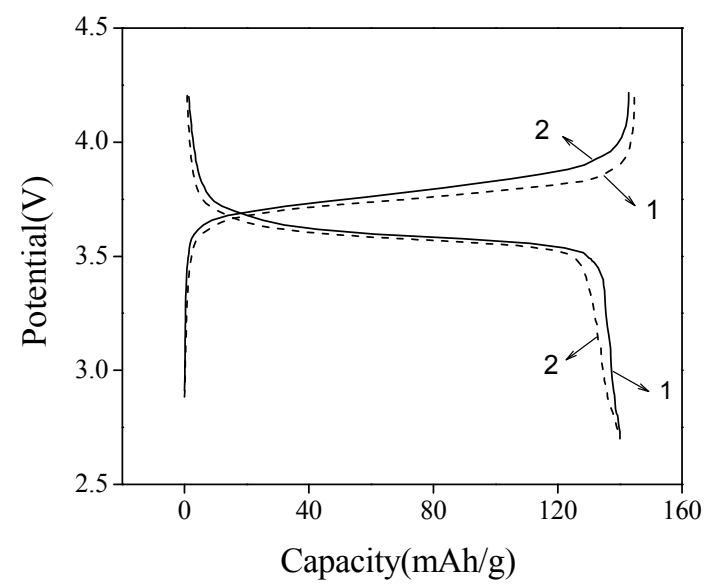

Fig. 6. Initial charge-discharge properties of $\mathrm{Li} / \mathrm{MPE} / \mathrm{LiFeO}_{4}$ cell with polymer electrolytes based on $\mathrm{C}-3$, at room temperature, $(0.1 \mathrm{C}$ rate, 2.7-4.3V).

$\mathrm{Li} / \mathrm{MPE} / \mathrm{LiFePO}_{4}$ cell is assembled. The electrochemical performance of the cell is evaluated by galvanostatic cycling under constant current of $0.1 \mathrm{C}$ between 2.7 and $4.3 \mathrm{~V}$. Fig. 6 shows the first charge-discharge profile of the $\mathrm{Li} / \mathrm{C}-3 / \mathrm{LiFePO}_{4}$ cell. The cell delivers initial discharge capacity of $140 \mathrm{mAh} / \mathrm{g}$, which is $82.4 \%$ of the theoretical capacity of $\mathrm{LiFePO}_{4}$. The $\mathrm{C}-3$ shows the highest porosity and contains the largest amount of electrolyte, and hence more liquid electrolyte can diffuse from the polymer electrolyte to the cathode, which leads to higher utilization of the active material. The ionic conductivity of the MPE may also affect the discharge property. This improved performance is attributed to the higher amorphous content, and electrolyte uptake and ionic conductivity of C-3.

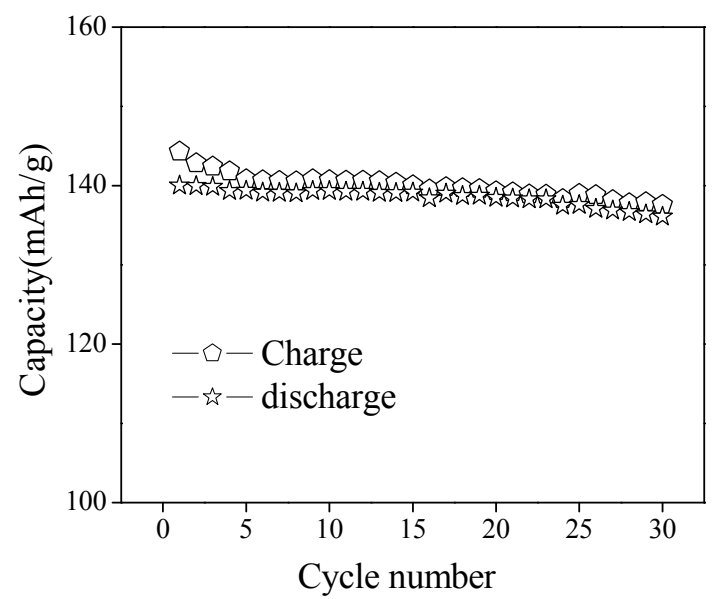

Fig. 7. Cycle properties of $\mathrm{Li} / \mathrm{MPE} / \mathrm{LiFeO}_{4}$ cell with polymer electrolytes based on $\mathrm{C}-3$, at room temperature, $(0.1 \mathrm{C}$ rate, $2.7-4.3 \mathrm{~V})$.

Fig. 7 presents the cyclic stability of the $\mathrm{Li} / \mathrm{MPE} / \mathrm{LiFePO}_{4}$ cell with $\mathrm{C}-3$ up to 30 cycles at $0.1 \mathrm{C}$ rate between 2.7 and $4.3 \mathrm{~V}$. It can be seen from Fig. 8 that the discharge capacity is slightly decreasing with numerous of cycling. After 30 cycles the cell with C-3 retains a discharge capacity of $136 \mathrm{mAh} / \mathrm{g}$, which is $97.1 \%$ of its initial discharge capacity. These results indicate the excellent efficiency of the C-3 polymer membrane to conduct the ions between electrodes during cycling processes, and have good compatibility with electrodes.

\section{CONCLUSIONS}

The MPEs based on P (VDF-HFP)/CNTs composites were prepared. With doping of $3 \% \mathrm{C}$ in the $\mathrm{P}$ (VDF-HFP), the ionic conductivity of MPE is improved to $4.36 \times 10^{-3} \mathrm{~S} / \mathrm{cm}$, the decomposition voltage of the MPE is greater than $5.5 \mathrm{~V}$, the electrochemical compatibility and battery performance is also improved. The high ionic conductivity can be ascribed to the low crystallinity and uniform interconnected porous structure of the membrane. The MPE based on $\mathrm{P}$ (VDF-HFP)/CNTs is suitable for the application in safe, reliable and long lasting $\mathrm{Li}$-ion batteries.

\section{ACKNOWLEDGMENT}

This work was financially supported by the Heilongjiang Province Youth Science Foundation (No. QC2010122).

\section{REFERENCES}

[1] H. P. Zhang, P. Zhang, Z. H. Li, M. Sun, Y. P. Wu, and H. Q. Wu, "A novel sandwiched membrane as polymer electrolyte for lithium ion battery," Electrochem. Commun, vol. 9, pp. 1700-1703, 2007.

[2] A. M. Stephan, "Review on gel polymer electrolytes for lithium batteries," Eur. Polym. J, vol. 42, pp. 21-42, 2006.

[3] Z. H. Li, H. P. Zhang, P. Zhang, G. C. Li, Y. P. Wu, and X. D. Zhou, "Effects of the porous structure on the conductivity of nanocomposite polymer electrolyte for lithium ion batteries," J. Membr. Sci, vol. 322, pp. 416-422, 2008.

[4] S. Rajendran, M. R. Prabhu, and M. U. Rani, "Ionic conduction in poly (vinyl chloride)/poly (ethyl methacrylate)-based polymer blend 
electrolytes complexed with different lithium salts," J. Power Sources, vol. 180, pp. 880-883, 2008.

[5] W. Pu, X. He, L. Wang, C. Jiang, and C. Wan, "Preparation of PVDF-HFP microporous membrane for Li-ion batteries by phase inversion," J. Membr. Sci, vol. 272, pp. 11-14, 2006.

[6] V. Aravindan, P. Vickraman, and K. Krishnaraj, " $\mathrm{Li}^{+}$ion conduction in $\mathrm{TiO}_{2}$ filled polyvinylidenefluoride-co- hexafluoropropylene based novel nanocomposite polymer electrolyte membranes with LiDFOB," Current Applied Physics, vol. 9, pp. 1474-1479.

[7] S. Ramesh and O. P. Ling, "Effect of ethylene carbonate on the ionic conduction in poly (vinylidenefluoride-hexafluoropropylene) based solid polymer electrolytes," Polym. Chem., vol. 1, pp. 702-707, 2010.

[8] A. Zalewska, M. Walkowiak, and L. Niedzicki, "Study of the interfacial stability of PVdF/HFP gel electrolytes with sub-micro and nano-sized surface-modified silicas," Electrochimica Acta, vol. 55, pp. 1308-1313, 2010.

[9] G. G. kumar, J. Shin, and Y. C. Nho, "Irradiated PVdF-HFP-tin oxide composite membranes for the applications of direct methanol fuel cells," Journal of Membrane Science, vol. 350, pp. 92-100, 2010.

[10] G. V. kumar, S. N. Kart hick, A. R. Sa thiya Priya, S. Ram alingam, and A. Subraman, "Effect of nanoscale $\mathrm{CeO}_{2}$ on PVDF-HFP-based nanocomposite porous polymer electrolytes for Li-ion batteries," $J$ Solid State Electrochem, vol. 12, pp. 1135-1141, 2008.

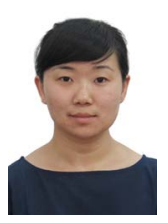

K. Kan was born in Harbin on May $14^{\text {th }}$ 1984. She graduated from Heilongjiang University, and got Master's degree in physical chemistry in July 2009.

She works in Daqing Branch of Heilongjiang Academy of Sciences in Daqing as a research assistant.

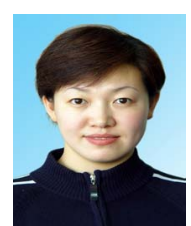

Y. Liu was born in Harbin on May 14th 1975. She graduated from Harbin Institute of Technology, and got a Master's degree in MBA in 2005.

She worked in Heilongjiang Academy of Science as an associate researcher.

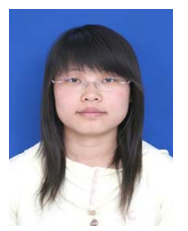

Y. Tian was born in Dehui on October $10^{\text {th }} 1986$. She graduated from Northeast Petroleum University, and got bachelor's degree in chemical engineering in July 2011.

She works in Daqing Branch of Heilongjiang Academy of Sciences in Daqing as a research assistant.

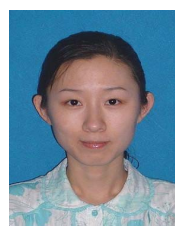

Q. S. You was born in Heilongjiang on October $18^{\text {th }}$ 1983. She graduated from Northeast Forestry University in 2007.

She works in Daqing Branch of Heilongjiang Academy of Sciences in Daqing as an engineer.

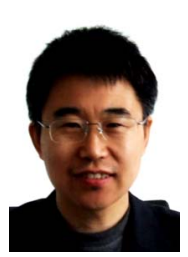

B. Y. Cui was born in Qinggang on November $26^{\text {th }}$ 1962. He graduated from Dalian University of Technology, and got a Master's degree in chemical machinery in 1988.

He works in Daqing Branch of Heilongjiang Academy of Sciences in Daqing as a senior engineer. 